\title{
A portable standalone wireless electric cell- substrate impedance sensing (ECIS) system for assessing dynamic behavior of mammalian cells
}

Uvanesh Kasiviswanathan ${ }^{1}$, Suruchi Poddar ${ }^{1}$, Chandan Kumar², Satyabrata Jit$^{2}$, Sanjeev Kumar Mahto ${ }^{1 *}$ and Neeraj Sharma ${ }^{1 *}$ (D)

\begin{abstract}
In this study, we have developed a wireless, portable, standalone, and simple electric cell-substrate impedance sensing (ECIS) system to analyze in-depth functional aspects of cellular functions on the surface of a co-planar metal electrode coated on conventional glass substrate using a low-cost circuitry and correlated it with an equivalent electrical circuit (EEC) model. Low-cost circuitry was used for studying the dynamic behavior of the mouse myoblast cells (C2C12) in a culture chamber. Further, the developed ECIS system was connected with 8-bit Arduino UNO microcontroller board for establishing a compact sized measuring unit, which can be placed inside a $\mathrm{CO}_{2}$ incubator to provide proper environmental condition for the biological cells during the entire measuring time. Integrating ZigBee RF module with the 8-bit Arduino UNO microcontroller board provides a wireless communication network. Theoretical calculation of the lumped-elemental electrical parameters associated with cellelectrolyte interface and metal-electrolyte interface was calculated. The calculation was performed by fitting the experimental impedance data to EEC model using least mean square method to determine the dynamic and vital functions of the mammalian cells such as proliferation (in real-time) with a change in intrinsic electrical parameters associated at any particular time point. Impedance measurements and the lumped-elemental electrical parameter were correlated with the respective microscopic images. The developed ECIS system was found to enable measuring of the extent of cellular proliferation over time. The compactness of the developed ECIS system integrated with the ZigBee RF module and the 8-bit Arduino UNO microcontroller board facilitates its utilization even when placed in the $\mathrm{CO}_{2}$ incubator for a prolonged time.
\end{abstract}

Keywords: Cellular function, Low-cost wireless system, Impedance measurements, Curve fitting, EEC model

\section{Introduction}

A cell is the basic building block of all organisms, which governs all functioning aspects of the complex heterogeneous biological system. Any abnormality in a single cell affects the entire characteristic behavior of tissues, organs, and even organisms (Das et al. 2014). Therefore, it

\footnotetext{
* Correspondence: skmahto.bme@iitbhu.ac.in; neeraj.bme@iitbhu.ac.in ${ }^{1}$ School of Biomedical Engineering, Indian Institute of Technology (Banaras Hindu University), Varanasi, Uttar Pradesh 221005, India Full list of author information is available at the end of the article
}

is necessary to understand the complex biological system at their cellular level appropriately to prevent and treat any complex diseases (Kasiviswanathan et al. 2020). The interaction between mammalian cells and artificial surfaces is fascinating for researchers on both scientific and medical grounds. The adhesion and spreading of mammalian cells is a very complex and multifactorial process. It depends on a variety of intracellular and extracellular predictors that play an important role in tissue architecture and integrity. Cells bind to other cells or an 
extracellular matrix (ECM) with the help of transmembrane proteins called integrins (Gelsinger et al. 2019). The integrins form a focal adhesion complex along with the actin filaments of the cell cytoskeleton (Horwitz 1997). The formation of focal adhesion triggers signals that direct proliferation, adhesion, differentiation, cell migration, and other morphological changes (Khalili and Ahmad 2015). Therefore, cell attachment formed is an important parameter while investigating the kinetics of cell spreading to artificial substrates. The commonly used techniques to monitor cell proliferation and viability include fluorescence microscopy, flow cytometry, and single endpoint assays such as WST-1 assay, XTT, MTT assay, and BrdU assay (Mondal and RoyChaudhuri 2018).

The traditional methods of monitoring cellular transformation mentioned above furnish us with either qualitative or semi-quantitative data apart from its requirement of labour-intensive protocols and expensive equipment. Moreover, these assays greatly compromise the consistency and reproducibility of the experiments, in addition to disturbing the normal physiological state of the cells resulting in their destruction (Prendecka et al. 2018). Therefore, to precisely monitor the cellular behaviors to external stimuli a real-time, non-invasive and label-free method is desirable. Since 1900s, impedance measurements of biological systems is used as nondestructive, label-free method to measure the electrical properties of cells (Pethig and Kell 1987). The electrical properties of the biological cells provide us an insight into its physiological, morphological, and pathological conditions, depending on the frequency of the electrical signal applied (Amini et al. 2018). The investigation of the dynamic behavior of mammalian cells including attachment, proliferation and spreading on a flat surface was first reported by Giaever and Keese 1984. The method was called electric cell-substrate impedance sensing (ECIS) that relies on measuring the change in electrical impedance by applying a constant current across the active sensing area, where the cells are allowed to form a cell monolayer after cell attachment. ECIS method seems to be a promising tool that presents a sensitive and continuous monitoring system of cellular parameters that vary during transformation (Plunger et al. 2012). In addition, impedance analysis-based system may provide quantitative information about the cellular parameters.

During the process of adhesion, the biological cell actively "senses" the physicochemical and structural properties of the underlying substrate to adapt and perform basic functions of the cell. Therefore, it is desirous to use biocompatible and non-toxic materials as electrode material for the purpose of cell impedance measuring system. According to literature, researchers have used gold $(\mathrm{Au})$, platinum $(\mathrm{Pt})$, indium tin oxide (ITO), and other organic electrode material such as poly (3, 4ethylenedioxythiophene): poly (styrene sulfonate) (PEDOT: PSS), reduced graphene oxide (rGO), and polyaniline (PANI); because of their biocompatibility and stable electrochemical properties. On the other hand, the use of such promising substrate materials significantly increased the cost and time of fabrication (Park et al. 2018; Pérez et al. 2018). It is known that the positively charged silver $\left(\mathrm{Ag}^{+}\right)$facilitates an increase in the cell adhesion process between bulk silver and negatively charged cell membrane through a strong electrostatic interaction (Abbaszadegan et al. 2015). In the separate works, Cao et al. 2013 and Gao et al. 2014 have reported that the silver nanoparticles (AgNPs) incorporation into a biomaterial facilitate an increase in the cellular functions such as adhesion, proliferation and spreading. The thin film coating of silver material has shown the properties of neither genotoxic nor cytotoxic; whereas, the good cell spreading is observed over the silver thin film (Bosetti et al. 2002). Hence, it can be inferred that the silver is a low-cost noble material having good antimicrobial property and biocompatibility. Therefore, in this study we have made an attempt to use silver-based electrode system.To the best of our knowledge, none of the researchers so far have considered silver (Ag) as the choice of electrode for fabricating a customized and effective ECIS system. In view of the above-mentioned facts, in the present work, we demonstrate development of a portable standalone ECIS system for studying the rate of mammalian cell proliferation using low-cost circuitry. It is a compact device comprising of ECIS system with ZigBee RF module interconnected with Arduino UNO microcontroller board for establishing wireless communication network and also for establishing as 8bit data acquisition system, which can be placed inside a $\mathrm{CO}_{2}$ incubator in order to facilitate proper environmental condition for the biological cells. The impedance measuring devices, which are available in the market for such kind of analysis, are costly and there is a high demand on the need of portable system for point-of-care applications especially in the field of bioengineering, healthcare, and environmental science. This appears as one of the major limiting factors in extensive utilization of such devices for the characterization of cell growth.

\section{Materials and method Material}

$22 \times 22 \mathrm{~mm}$ cover glass (Bluestar, India) was procured and used as a substrate to fabricate the device. Mouse myoblast $(\mathrm{C} 2 \mathrm{C} 12)$ cell line was received from NCCS, Pune, India. Dulbecco's modified Eagle's medium (DMEM) high glucose, fetal bovine serum (FBS), penicillin-streptomycin $(100 \mu \mathrm{g} / \mathrm{mL}$ ), and gelatin (cell culture tested) were received from HiMedia, India. OP07 
OP-AMP IC (Analog Devices Inc., USA), 50 MHz Function Generator (Scientech Technologies Pvt Ltd., India), ICL 8038 Signal Generator IC (Intersil America Inc., USA), $25 \mathrm{MHz}-500 \mathrm{MSa} / \mathrm{s}$ Digital Storage Oscilloscope (Nvis 102CT, Nvis Technologies Pvt Ltd., India), Genuino UNO (Arduino.cc, USA), Computer (HP, i5 4 GB RAM Windows 10 home, Singapore), and $\pm 9 \mathrm{~V}$ battery were used in performing the experiments.

\section{Microelectrode design and fabrication}

The glass substrate was cleaned thoroughly using standard wet chemical cleaning procedures (Kumar et al. 2017) and the cleaned substrates were loaded into the thermal evaporation chamber (Hind High Vac, model smart coat 3.0 A). Research grade silver metal (99.99\%, Taewon Scientific Co. Ltd., South Korea) of thickness $(t$ $\approx 100 \mathrm{~nm}$ ) was deposited on the glass substrate. A maximum electrode gap of $4 \mathrm{~mm}$ was fabricated in order to provide sufficient gap for improved cell adhesion on the surface and to provide a proper imaging facility. The active layer's dimensions are of $1.5 \mathrm{~mm}$ wide and $4 \mathrm{~mm}$ length as shown in Fig. 1a.

For maintaining the culture media, Cliklok Micro Centrifuge (Tarsons Product Pvt Ltd., India) tube was cut and used as described (Kasiviswanathan et al. 2020) on the top of the microelectrode fabricated glass substrate. In our study, we used microwell culture chamber as a customized cell-culture chamber integrated with a co-planar microelectrode. Customized culture chamber was shown in Fig. 1b.

\section{Cell culture procedure}

Mouse myoblast cells $(\mathrm{C} 2 \mathrm{C} 12)$ were maintained in a humidified, 5\% $\mathrm{CO}_{2}$ incubator (Galaxy 170S, Eppendorf) at $37{ }^{\circ} \mathrm{C}$ with DMEM high glucose medium containing 10\% FBS and 1\% penicillin-streptomycin (Vajanthri et al. 2019). The microwells were coated with $2 \%$ gelatin solution kept overnight and washed twice with phosphate buffer saline (PBS) before using
(Balavigneswaran et al. 2018). The subcultured cells were grown inside the fabricated chamber. The cells were seeded at a density of 1200 cells/well, in order to visualize cellular connectivity for an optimal duration and the medium was changed prior to every observation.

\section{Voltage controlled constant current source (VCCS) unit construction and testing}

In principle, impedance based measurements work according to Ohm's Law which is expressed as $Z=V / I$ where $Z=$ impedance, $V=$ voltage, and $I=$ current. Cells when interact and attach to the electrodes deposited on the substrate act as insulators thus contributing towards an increase in impedance (Prendecka et al. 2018). The measure of opposition to the flow of electric current of cultured cells depends on various factors such as cell density covering the electrodes, morphology of the cells, type of cells and cellcell gaps (Cho 2011). Hence, we monitored the change in dynamic behavior of the mammalian cells under a voltage controlled constant current source (VCCS) by introducing an in vitro impedance analysis technique (Park et al. 2018). The developed system is advantageous considering the studies of dynamics of an adherent mammalian cells using miniaturized metal microelectrode. The experiments were performed in real-time, which makes it a more superior method over the conventional microscopic observations (Siddiquei et al. 2010; Szulcek et al. 2014).

Here, we used OP-AMP as integrator (or inverting amplifier) with two-voltage buffer circuit at both ends in order to avoid any loading effect. A voltage controlled constant current was supplied across the microelectrode terminals and the change in electrical potential was measured in terms of either increase or decrease in electrical impedance over the range of frequency (Liu et al. 2009; Park et al. 2018; Pérez et al. 2018).

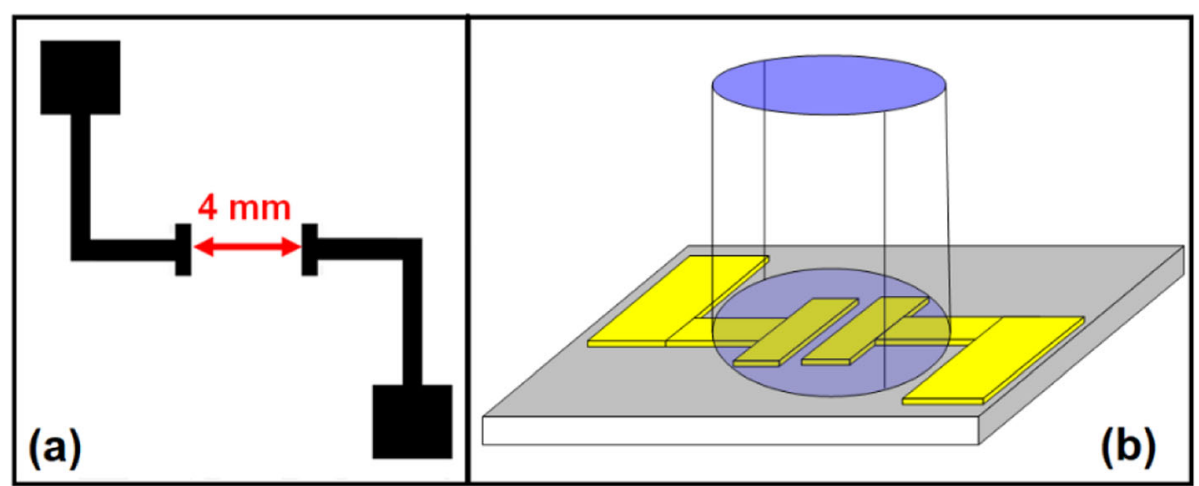

Fig. 1 a Microelectrode design pattern used. b Customized cell-culture chamber developed 
Output voltage of OP-AMP is given by

$$
v_{\text {output }}=-\left(\frac{v_{\text {input }}}{R_{1}}\right) R_{f}
$$

where

$$
\frac{v_{\text {input }}}{R_{1}}=i_{\text {input }}
$$

$R_{f}$ is variable and it is decided by the mammalian cell functioning aspects in the medium on the electrodes, while $R_{1}$ is fixed $(\approx 10 \mathrm{k} \Omega$ ), and these drives the gain of the developed circuit (ECIS setup) with a current limiting resistor $\left(R_{\text {limit }} \approx 1 \mathrm{M} \Omega\right)$.

Gain of inverting amplifier is

$$
v_{\text {output }}=-i_{\text {input }} \cdot R_{f}
$$

Apart from this, our design does not contain any other electronic components because it suffices the requirements of measuring the activities of any biological sample. The developed ECIS system is calibrated using standard resistor values (varying from few ohms to mega ohms) while keeping $R_{1}$ value constant $(\approx 10 \mathrm{k} \Omega$ ) with excitation frequency $2.5 \mathrm{kHz}$ and excitation voltage of about $400 \mathrm{mV}$ ( $\left.V_{\text {Peak - Peak }}\right)$. The corresponding graph is given in Fig. $4 \mathrm{~d}$ with $R^{2} \approx 1$. However, calibration plot using different resistor values $R_{1} \approx 100 \Omega, 1 \mathrm{k} \Omega$, and 100 $k \Omega$ is given in supplementary information (Figure S1). An optimum level of current and voltage is required in order to avoid affecting the cellular integrity (Park et al. 2018). Hence, the developed ECIS setup was calibrated by fixing $1 \mu \mathrm{A}$ current and $400 \mathrm{mV}\left(V_{P_{-} P}\right)$. Hence, the developed ECIS setup showed its functioning over the frequency range of $500 \mathrm{~Hz}$ to $60 \mathrm{kHz}$, to measure the behavior of the cell without affecting the biological environment of the mammalian cells.

The impedance $(Z)$ is written as

$$
|\mathrm{Z}|=\frac{\mathrm{V}_{\text {output }}}{i_{\text {input }}}\left[|\mathrm{Z}| \approx \mathrm{R}_{f}\right]
$$

The impedance of any two-terminal network can be represented as a complex quantity, which is defined in Cartesian form as

$$
\mathrm{Z}=\mathrm{R}+j \mathrm{X}_{C}
$$

Where the real part is resistance $R$, and the imaginary part is reactance $X_{C}$. The magnitude $(|Z|)$ and phase $(\phi)$ of impedance was calculated using Eqs. 6 and 7, respectively.

$$
|Z|=\sqrt{R^{2}+X_{C}^{2}}
$$

$$
\phi=\tan ^{-1}\left[\frac{X_{C}}{R}\right]
$$

\section{Equivalent electrical circuit Model for the cell-electrode interface}

The bio-impedance analysis method of any biological medium such as organ, tissue, and cells was used to characterize the changes induced by the electrical field on that medium. Hence, researchers have reported electrical modelling of the cells using the combination of resistance, capacitance, and constant phase elements to divulge the information about the cell adhesion, proliferation and differentiation (Cho 2012; Maundy and Elwakil 2012; Müller et al. 2011; Pérez et al. 2018). Further such devices were used as biosensors for monitoring the cell physiology in the presence of the bioactive agents (such as external stimuli, and drug) (Müller et al. 2011; Pan et al. 2019). In addition, the cell membrane integrity and apoptosis of cells in presence of bioactive compounds have also been predicted (Parviz et al. 2017; Siddiquei et al. 2010; Wegener et al. 2000). Hence, by fitting the experimental data with an equivalent electrical circuit, one can calculate the theoretical relationship between the electrode-electrolyte and electrolyte-cell interface with and without the biological cells inoculated into the culture media (Kenchetty and Miura 2019). Further, EEC model for the cell-electrode interface is discussed in the "Results and discussion" section.

\section{Complete electric cell-substrate impedance sensing (ECIS) system}

To reduce the measurement system cost, we used locally available materials to construct an impedance analyzer in our laboratory. The measurement system consists of three units as follows: (1) a sinusoidal signal generation unit, where we will change the frequency and voltage needed with a current- and voltage-limiting circuit; (2) inverting amplifier circuit (which will act as an impedance analyzer unit), (the schematic diagram is given in Fig. $2 \mathrm{a}$ and calculation procedure is given already in the ECIS section); (3) data acquisition system, i.e., Digital storage oscilloscope (DSO)-wired and Arduino Genuino UNO [both wired (Uvanesh et al. 2015) and wireless] was used for analyzing the change in electrical potential across the microelectrode. It displayed the values in Arduino Sketch software for wired communication and a pair of ZigBee RF (S1) module (one for wireless data transmission and other for receiving purpose) was used for wireless communication as shown in Fig. 2b.

A sinusoidal signal from the signal generator was given to the feedback region of the inverting 


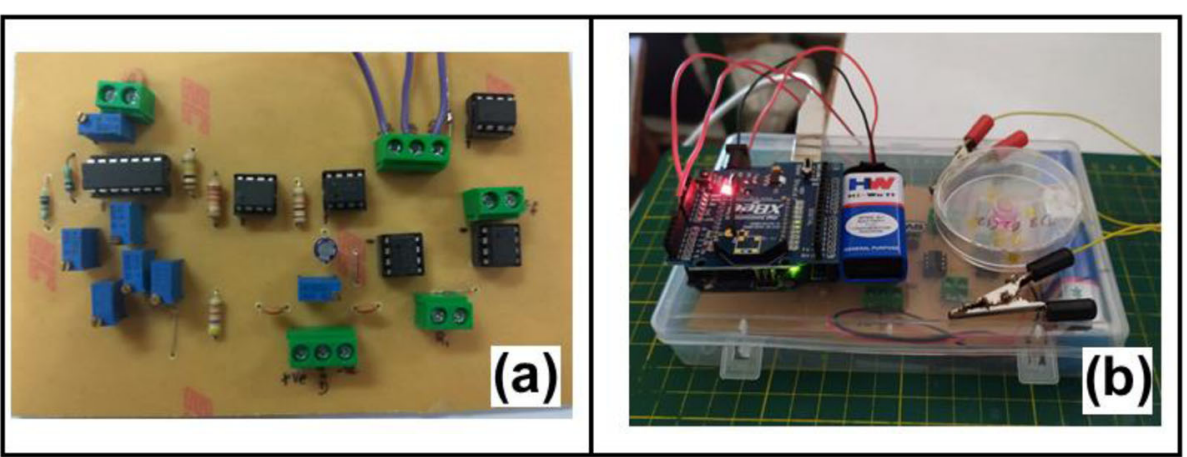

Fig. 2 a Actual ECIS system and $\mathbf{b}$ constructed experimental (wireless) setup used with $2.5 \mathrm{kHz}$ exciting frequency

amplifier through voltage buffer and a current limiting resistor $(1 \mathrm{M} \Omega)$ to avoid loading effect and to restrict the current flow to $1 \mu \mathrm{A}$. The microelectrodes were connected to the feedback region of inverting amplifier using enameled copper wire. When $\mathrm{C} 2 \mathrm{C} 12$ cells proliferate, a corresponding change in voltage can be observed. Case 1: in the wired-type ECIS measurement system, the change in voltage across the low-cost circuitry was simply acquired by 8 -bit Arduino UNO microcontroller board, and the corresponding change in impedance value was calculated and displayed in serial monitor of Arduino Sketch software. Case 2: while for establishing a wireless communication network, ZigBee RF module was interconnected with 8-bit Arduino
UNO microcontroller board and the corresponding change in impedance value was calculated and sent to the receiving end that is displayed on the serial monitor of Arduino Sketch software. The detailed measurement process using the designed ECIS system is illustrated in Figure S3 as the flowchart. The ZigBee RF was used for the wireless communication protocol which is an IEEE 802.15.4-based protocol. A complete and detailed schematic representation of the developed device is shown in scheme 1 and a cost comparison table is provided in supplementary file, Table S1. To avoid the loading effect and (any) leakage current from the detection unit, another voltage buffer is placed in-between inverting amplifier and detection unit.

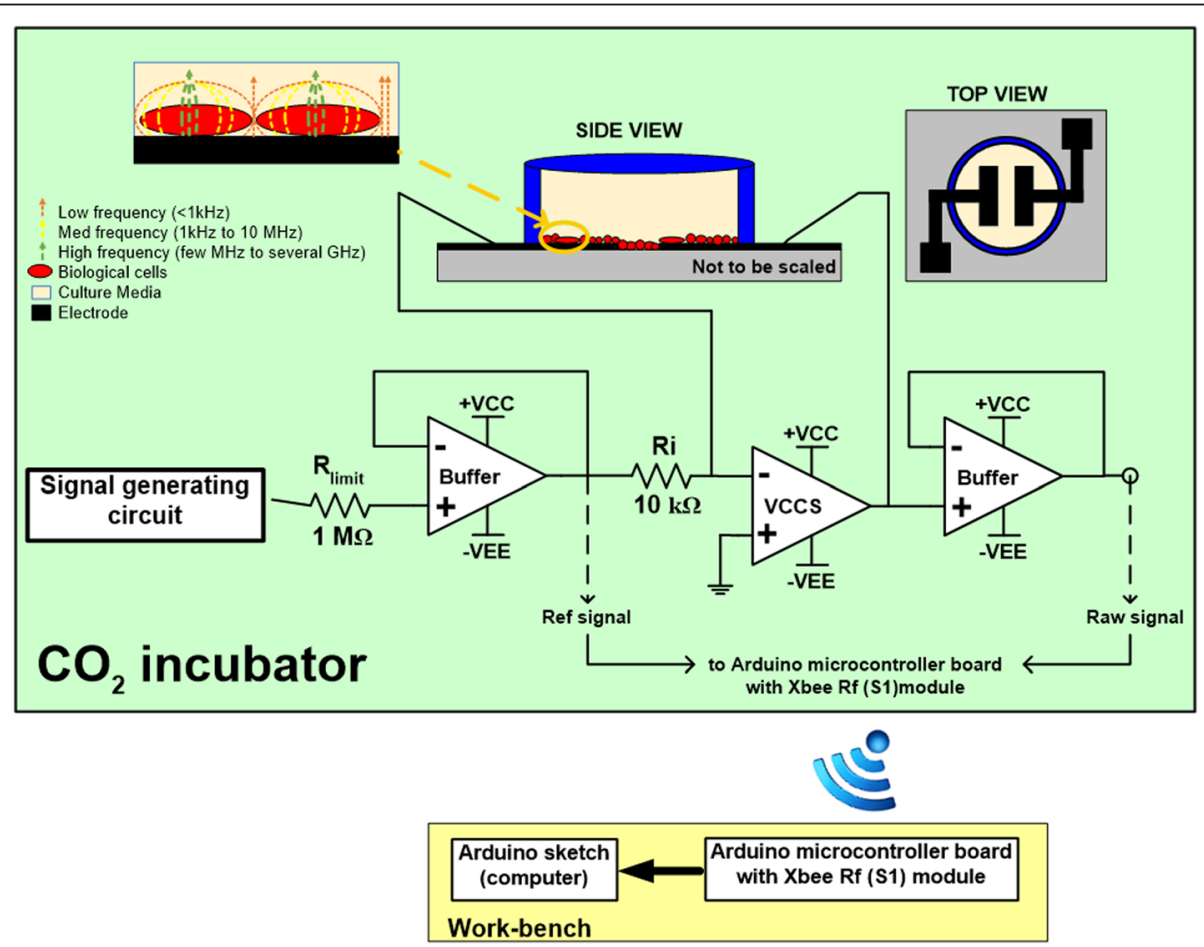

Scheme 1 Schematic pictorial representation of the developed device 


\section{Results and discussion}

The basic cell growth assay was performed by seeding a lower population of $\mathrm{C} 2 \mathrm{C} 12$ cells into the culture chamber due to its rapidly growing nature (Jing 2012) in order to delay confluence and also to collect data of cellular transformations over a longer period. It can be inferred from Fig. 3 that $\mathrm{C} 2 \mathrm{C} 12$ cells attached, spread, and proliferated on gelatin-coated Ag electrodes. $\mathrm{C} 2 \mathrm{C} 12$ cells attained their characteristic spindle shape with defined nucleus and maintained the same throughout impedance measurements; indicating that cellular adhesion and proliferation were not disturbed even during acquisition of the readings through the provided input voltage and current from the designed ECIS system. Hence, a tiny change in dynamic behavior of the cell was observed as an increase in magnitude of impedance (as shown in Fig. 4a). After $3 \mathrm{~h}$ of culture, the shape of the cells was observed to be spheroid-like structure (as shown in Fig. 3a); indicating that the cells were either not at all adhered or still preparing themselves to undergo through the process of adhesion (i.e., early phase of cell adhesion) on the surface of the substrate. Typically, this phenomenon (i.e., micromotion of cells) was observed as a sudden increase in magnitude of impedance (as shown in Fig. 4a) through our developed ECIS device. The sudden increase in impedance was most likely due to the random and free-motion (Giaever and Keese 1991) of the biological cells suspended in the culture medium. Furthermore, the results were found in compliance with other reported papers concerning the phenomenon of the micromotion of the cells well before the adhesion on the substrate (i.e., the experimental data at $3 \mathrm{~h}$ ) (Lo et al. 1995; Siddiquei et al. 2010; Tsong 1989; Zimmermann and Vienken 1982). Ideally, during the adhesion process, the cells suspended into the culture medium (ionic solution) adhere to the surface based on the material property by establishing a mechanical link between the cell membrane and the substrate with the help of focal adhesion transmembrane proteins, i.e., integrin $\alpha v \beta 3$ and plaque proteins (paxillin, vinculin, etc.) (Sales et al. 2019). After $6 \mathrm{~h}$ of culture, we observed a significant change in the cell morphology: the cells became flatten upon adhesion on the substrate, which was evidenced through the microscopic observation as represented in Fig. 3b. Due to such changes, a noted increase in the impedance value was also observed. Further, through the normalized impedance data (as represented in Figure S4b), we observed that changes in the cellular morphology correspondingly influence the impedance values, as shown in Fig. 4.

In order to qualitatively evaluate our hypothesis and the impedance results, we studied the morphological changes and rate of cell proliferation in terms of increase in number (as shown in Figure S4a) using microscopic imaging technique. The cell number calculation was performed manually by considering five images and the average and SD values are given in shown in Figure S4a. Figure 3 shows the microscopic images of $\mathrm{C} 2 \mathrm{C} 12$ cells grown on a substrate at various time points and the respective impedance values recorded as displayed in Fig. 4. Impedance analysis of the cells was performed at various time points with modulating time gap in order to avoid disturbance in the

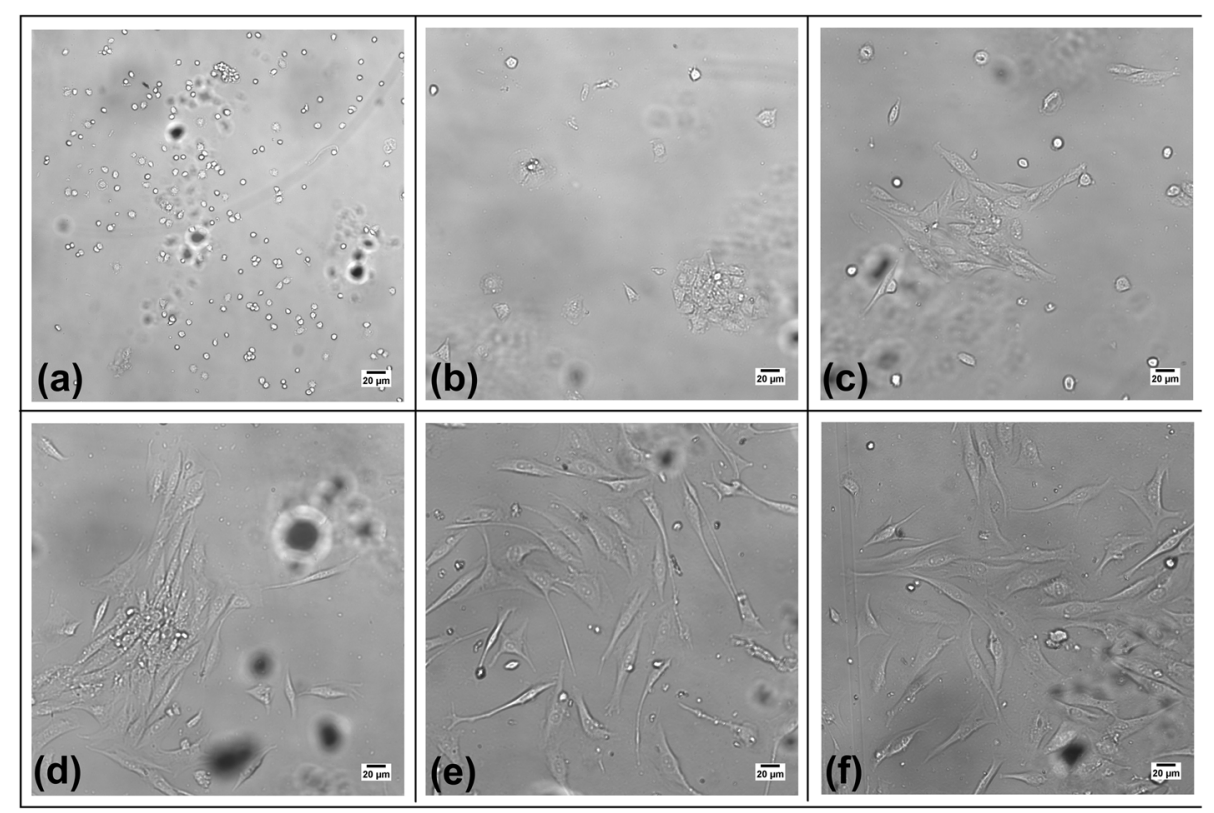

Fig. 3 shows the morphological changes of C2C12 cells at various time point. a 3 h, b 6 h, c 18 h, d 32 h, e 48 h, and f 72 h; Scale bar $20 \mu m$ 


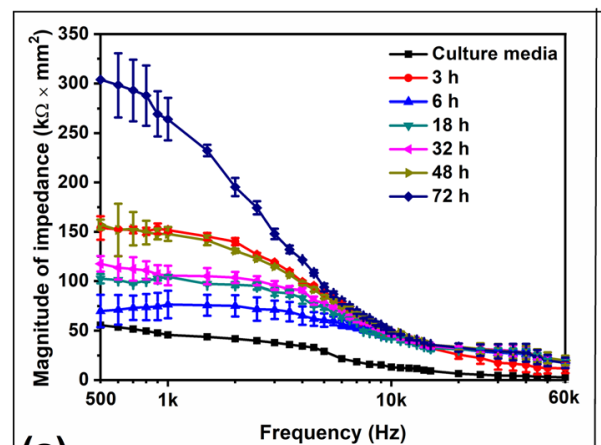

(a)

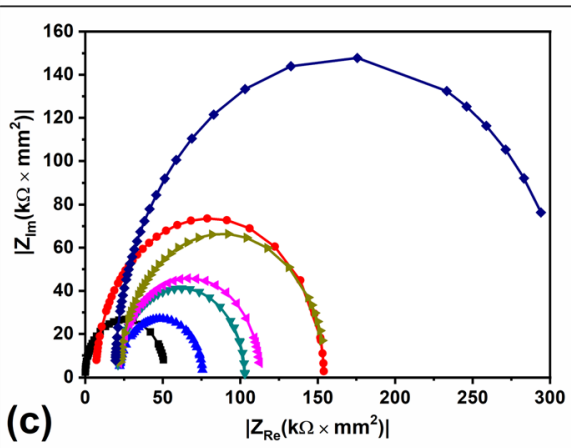

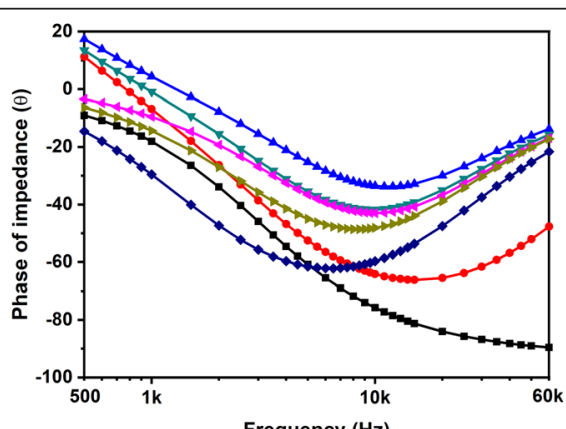

(b)

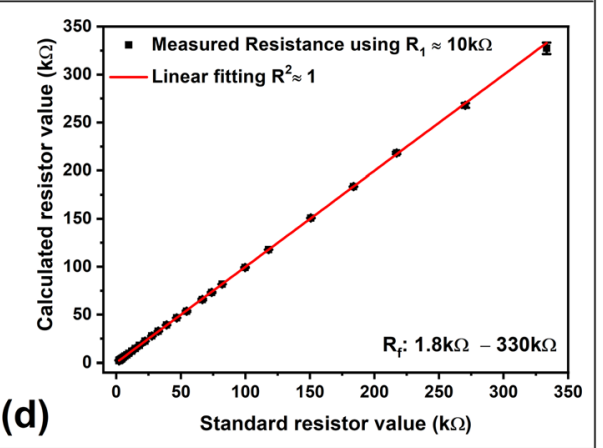

Fig. 4 Change in cell proliferation with respect to average magnitude of impedance over the calibrated area. $\boldsymbol{a}$ Frequency vs. magnitude. $\boldsymbol{b}$ Frequency vs. phase. $\boldsymbol{c}$ Cole-Cole plot shows the change in semi-circle diameter due to the change in transfer of electrons between the metalelectrode interface resistance. $\boldsymbol{d}$ A calibration plot using commercially available resistors shows that the developed system is capable of measuring the impedance value with an accuracy of about $R^{2}=0.999$

developed biological environment. All the experiments were done in $n=5$ and the average data were represented.

Biological entities are supremely heterogenic in nature that comprises of numerous non-conductive components that imparts impedance. Cells contain intracellular fluid that is enveloped with the phospholipid bilayer. Both intracellular and extracellular fluid of the cells contain ions that designates them as electrolytes ( $\mathrm{Lu}$ et al. 2013). The embedded transmembrane proteins within the phospholipid bilayer regulate the transport of ion and water across cellular membrane. Additionally, the cell membranes also consists of sphingolipids and cholesterol that are very poor electrical conductors at lower frequencies but significantly adds up to the impedance values (Coffman and Cohen 2013). Therefore, the variation in the values of impedance reflects an alteration in the cellular physiology arising due to cell spreading and attachment. Despite measuring the presence of living cells, impedance value curtails the influence of dying cells. The disintegration of the plasma membrane of the fading cells no longer serves as a barrier to the current. We observed as the cells began to interact and proliferate on the electrodes the resistance values started to surge resulting in an increased impedance; while the change in phase of impedance was directly correlated with the corresponding change in the morphology of the biological cells (Rahman et al. 2008). Thus, from the phase plot (as shown in Fig. 4b), it was inferred that the change in cell morphology significantly influences the experimental output. Further, we have shown the ColeCole (Nyquist) plot (Fig. 4c) for the cell growth at various time points, wherein we have found a noticeable change in diameter of the semi-circle that could be attributed to the change in transfer of electrons between the metal-electrode interface to the cell-electrolyte interface. This phenomenon is observed most likely due to change in the free space in and around the metal microelectrode (Pasqualotto et al. 2012), and it also reflects the degree of homogeneity present. The deviation in the semi-circle is most likely due to the change in degree of homogeneity, conductivity and phase shift of the constant phase element $\left(Z_{\mathrm{CPE}}\right)$. The $Z_{\mathrm{CPE}}$ depends on double-layered capacitance $\left(Q_{\text {cell }}\right)$, which is modulated by the empirical parameter " $n$." Therefore, this could be due to change in the cell morphology during exhibition of the basic cellular functions such as cell attachment, spreading and proliferation. The cell morphology of $\mathrm{C} 2 \mathrm{C} 12$ cell in and around the metal electrode is shown in Figure S5. Further, we also observed that silver metal as an electrode favoured the ECIS-based measurement for a prolonged duration, i.e., up to $72 \mathrm{~h}$. However, due 
to its corrosion after $72 \mathrm{~h}$, further analysis was not considered very significant.

When an excitation pulse is given to the microelectrode system, a transfer of electron from the metal surface to the solution or electrolyte (especially to the ionic carrier present in the electrolyte) takes place, which leads to development of a charged double-layer across the electrode to form electrode-electrolyte interface. The developed charged double-layered interface is directly related to a capacitance $\left(C_{\mathrm{dl}}\right)$ in parallel with a resistance $\left(R_{\mathrm{dl}}\right)$, which together represented by a constant phase element $\left(\mathrm{CPE}_{\text {et }}\right)$ with an empirical parameter " $n$ " $(0 \leq$ $n \leq 1)$. If $n=1$, then the system is related to an ideal capacitor; whereas if $n=0$, then the system is related to an ideal resistor and the impedance of $\mathrm{CPE}_{\text {et }}\left(Z_{\text {CPEet }}\right)$ can be calculated by an equation 10 . Further, constant phase element $\left(\mathrm{CPE}_{\mathrm{et}}\right)$ of electrode-electrolyte interface is used to describe several other aspects such as surface roughness of the electrodes, non-uniform current distribution, and distribution of reaction rates, among other processes. While the constant phase element $\left(\mathrm{CPE}_{\text {cell }}\right)$ of biological cell is used to model the cell-layer capacitance, which is due to a space charge distribution on either side of the membrane.

To fit the experimental data, researchers have used Cole-Cole model (Fig. 5a) (Elwakil 2012) and FrickeMorse model (Fig. 5c) (Cho 2012) to understand the physiological elements of the biological cell or tissue by correlating it with the respective passive electrical element. The resistance can be used to represent the ionic conductions, capacitance can be used to represent the polarization effects of the cell-membrane, and constant

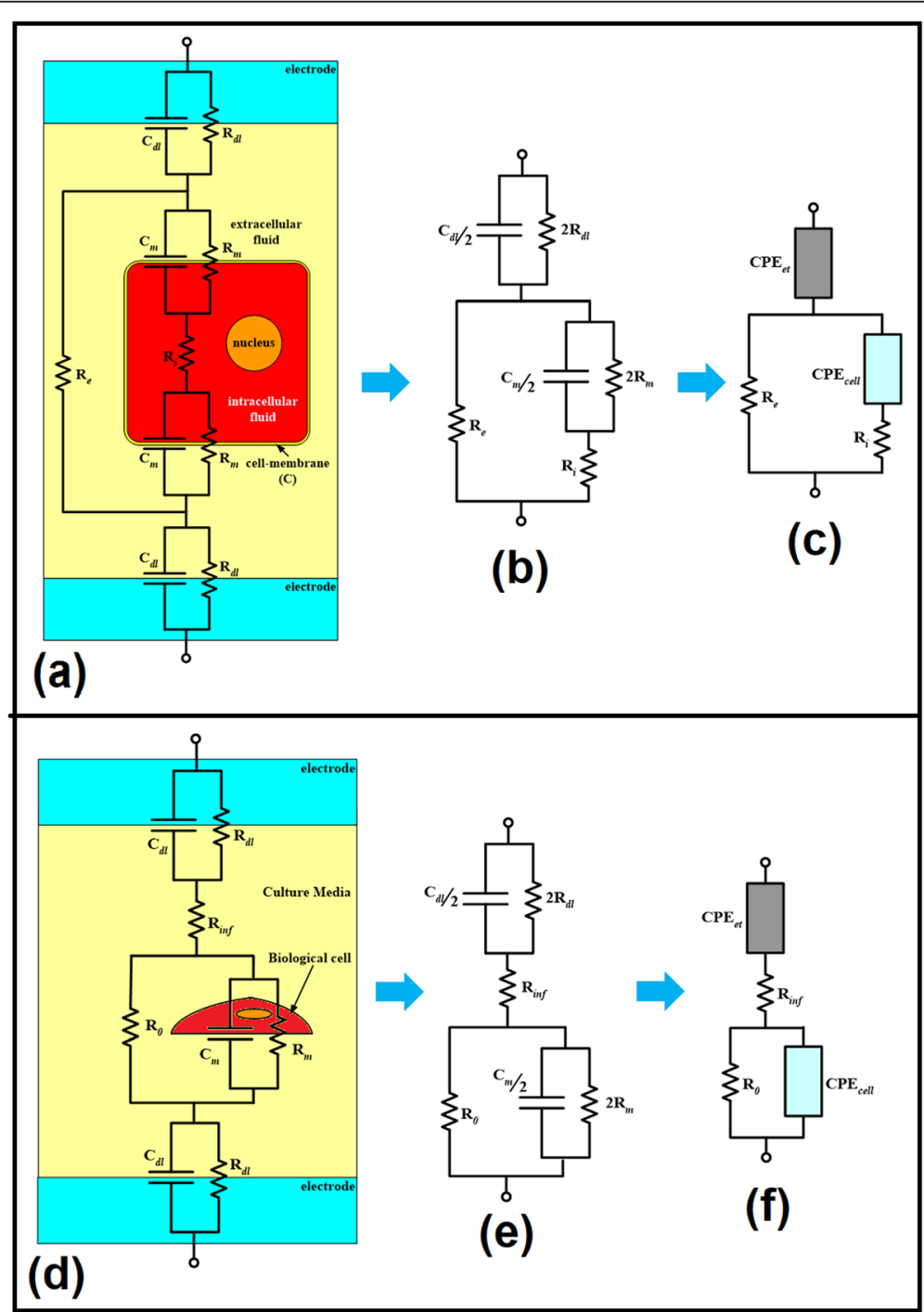

Fig. 5 Equivalent circuit model of biological cells. a Fricke-Morse model. c Modified Fricke-Morse model. d Cole-Cole model. f Modified Cole-Cole model. While $\mathbf{b}$ and $\mathbf{e}$ are simplification steps 
phase element was used to represent and characterize the size of cells or the tissue (Cho 2012; Elwakil 2012). Therefore, any tiny quantitative change in these passive electrical parameters can divulge the functional aspects of biological cells developed as a function of its basic cellular functions. Further, it is known that the cell membrane acts as a selective ion barrier to perform various cell functions (Kenchetty and Miura 2019; Xiaoa and Luong 2010); hence, the cell membrane predominately shows more capacitive than that of being resistance. Figure 5a shows the Fricke-Morse equivalent electrical circuit model (Akulov et al. 2015; Bera 2018; Kyle et al. 2004), for the biological cells with its simplification process and Table 1 shows the corresponding model parameters of the equivalent electrical model extracted. Generally, the biological cell can be represented by its own membrane's resistance $\left(R_{m}\right)$ and capacitance $\left(C_{m}\right)$ in parallel, while the inner region excluding the nucleus, i.e., the cytoplasm can be represented as a resistance $\left(R_{i}\right)$ and the outer region (extracellular fluid) can be represented as a resistance $\left(R_{e}\right)$ or solution resistance $\left(R_{\text {sol }}\right)$, though it has some defined electrical conductivity. Hence, in the Fricke-Morse model, the extracellular resistance $\left(R_{e}\right)$ is kept at one arm in parallel with the intracellular resistance $\left(R_{i}\right)$ and the cell-membrane $(C)$. The cell membrane $(C)$ consists of membrane resistance $\left(R_{m}\right)$ in parallel with and membrane capacitance $\left(C_{m}\right)$ in one arm. As the cell membrane $(C)$ is nothing but a selectively permeable membrane made up of a tiny lipid bilayered film; hence, it allows some of the ionic molecule/components into the cell body while it is partially permeable to some of the other organic and synthetic molecular components (such as lipid, water molecules, and drug). Therefore, the cell membrane is considered as a dielectric medium or material due to its less conductivity nature. However, to represent the non-homogeneous constant present in the biological cell, the cell membrane $(C)$ is generally represented with a constant phase element $\left(\mathrm{CPE}_{\text {cell }}\right)$. Thus, the Fricke-Morse model was modified as shown in Fig. $5 c$. Hence, the modified Fricke-Morse model will provide extracellular resistance $\left(R_{e}\right)$ in the one arm in parallel with the intracellular resistance $\left(R_{i}\right)$, and constant phase element $\left(\mathrm{CPE}_{\text {cell }}\right)$ will be in another arm, while the electrode-electrolyte interfacing component $\mathrm{CPE}_{\text {et }}$ is kept in series. Meanwhile, the Cole-Cole electrical equivalent circuit (shown in Fig. 5d) is used to analyze the dielectric dispersion or heterogeneity and morphological changes present in any biological medium (Trainito et al. 2015). Herein, the Cole-Cole model consists of two resistance in order to represent both higher and lower frequency components (resistance $R_{\text {inf }}$ and $R_{0}$ ) and a capacitance element to represent the cell membrane. Therefore, the higher frequency components, i.e., serial resistance $\left(R_{\text {inf }}\right)$ in one arm, while the other arm has a lower frequency component resistance $\left(R_{0}\right)$ in parallel with a cell membrane $(C)$. Later, the cell membrane $(C)$ is being replaced by a constant phase element $\left(\mathrm{CPE}_{\text {cell }}\right)$ in order to represent the non-homogeneity present in the biological cells. Thus, the Cole-Cole model was modified as shown in Fig. 5f. These $\mathrm{CPE}_{\text {cell }}$ is used to extract the heterogeneity and morphological change present in the biological cells of a complex biological medium. Similarly, as like in the Fricke-Morse model, the electrode-electrolyte interface was represented by constant phase element $\left(\mathrm{CPE}_{\mathrm{et}}\right)$ Hence, the modified Cole-Cole model will have $\mathrm{CPE}_{\text {et }}$ in series with the serial resistance $\left(R_{\text {inf }}\right)$ in one arm while another arm, it will have a resistance $\left(R_{0}\right)$ and $\mathrm{CPE}_{\text {cell }}$ in parallel.

Here, in this work, the measured impedance data were fitted using non-linear least mean square curve fitting method (as shown in Figure S2) to analyze the nonuniformity present in the biological cells using modified

Table 1 Analytical values through an equivalent electrical circuit model of adherent cell-electrolyte-electrode system (fitting data derived from best of five developed microelectrode system)

\begin{tabular}{|c|c|c|c|c|c|c|c|}
\hline FM model & $a_{e t}$ & $C P E_{e t}(\mathrm{~F})$ & $a_{\text {cell }}$ & $C P E_{\text {cell }}(\mathrm{F})$ & $R_{i}(\mathrm{k} \Omega)$ & $R_{e}(\mathrm{k} \Omega)$ & $R^{2}$ \\
\hline $6 \mathrm{~h}$ & $8.78 \mathrm{E}-03 \pm 7.84 \mathrm{E}-06$ & $1.13 \mathrm{E}-02 \pm 7.32 \mathrm{E}-05$ & $0.83 \pm 0.05$ & $9.46 \mathrm{E}-06 \pm 4.21 \mathrm{E}-06$ & $1.21 \mathrm{E}-02 \pm 1.27 \mathrm{E}-04$ & $15.71 \pm 3.44$ & $0.98 \pm 1.17 \mathrm{E}-03$ \\
\hline $18 \mathrm{~h}$ & 8.76E-03 $\pm 4.45 E-05$ & $1.11 \mathrm{E}-02 \pm 4.58 \mathrm{E}-04$ & $0.90 \pm 0.08$ & $5.52 \mathrm{E}-06 \pm 4.18 \mathrm{E}-06$ & $1.18 \mathrm{E}-02 \pm 5.73 \mathrm{E}-04$ & $19.38 \pm 1.13$ & $0.99 \pm 4.02 \mathrm{E}-03$ \\
\hline $36 \mathrm{~h}$ & 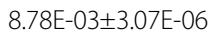 & 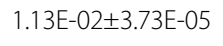 & $0.92 \pm 0.03$ & $3.88 \mathrm{E}-06 \pm 1.47 \mathrm{E}-06$ & $1.21 \mathrm{E}-02 \pm 4.47 \mathrm{E}-05$ & $24.53 \pm 2.93$ & $0.99 \pm 2.45 E-04$ \\
\hline $48 \mathrm{~h}$ & 8.73E-03 $\pm 5.89 E-06$ & 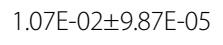 & $0.98 \pm 0.08$ & $2.03 \mathrm{E}-06 \pm 1.59 \mathrm{E}-06$ & 1.14E-02 $\pm 8.74 \mathrm{E}-05$ & $37.22 \pm 5.95$ & $0.99 \pm 5.18 \mathrm{E}-03$ \\
\hline $72 \mathrm{~h}$ & $8.67 E-03 \pm 6.31 E-05$ & $9.82 \mathrm{E}-03 \pm 7.20 \mathrm{E}-04$ & $0.99 \pm 0.06$ & $1.31 \mathrm{E}-06 \pm 9.02 \mathrm{E}-07$ & $1.05 \mathrm{E}-02 \pm 7.74 \mathrm{E}-04$ & $45.79 \pm 10.29$ & $0.99 \pm 2.27 \mathrm{E}-03$ \\
\hline CC model & $R_{\text {inf }}$ or $R_{\text {so }}(\mathrm{k} \Omega)$ & $a_{e t}$ & $C P E_{e t}(\mathrm{~F})$ & $R_{0}(\mathrm{k} \Omega)$ & $a_{\text {cell }}$ & $C P E_{\text {cell }}(\mathrm{F})$ & $R^{2}$ \\
\hline $6 \mathrm{~h}$ & $5.81 \mathrm{E}-11 \pm 3.09 \mathrm{E}-11$ & $0.33 \pm 0.08$ & $3.79 \mathrm{E}-02 \pm 3.22 \mathrm{E}-02$ & $13.52 \pm 2.79$ & $0.88 \pm 0.06$ & $6.64 \mathrm{E}-06 \pm 3.37 \mathrm{E}-06$ & $0.98 \pm 2.22 \mathrm{E}-03$ \\
\hline $18 \mathrm{~h}$ & $3.61 \mathrm{E}-11 \pm 0.01 \mathrm{E}-12$ & $0.48 \pm 0.01$ & 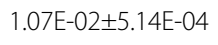 & $18.48 \pm 0.02$ & $0.84 \pm 0.01$ & $8.58 \mathrm{E}-06 \pm 1.41 \mathrm{E}-06$ & $0.99 \pm 3.07 \mathrm{E}-03$ \\
\hline $36 \mathrm{~h}$ & 3.95E-11 $\pm 4.75 E-12$ & $0.60 \pm 0.12$ & $5.65 \mathrm{E}-03 \pm 1.95 \mathrm{E}-03$ & $22.60 \pm 1.01$ & $0.95 \pm 0.02$ & $3.04 \mathrm{E}-06 \pm 1.07 \mathrm{E}-06$ & $0.99 \pm 1.62 \mathrm{E}-04$ \\
\hline $48 \mathrm{~h}$ & $3.61 E-11 \pm 0.01 E-12$ & $0.68 \pm 0.03$ & 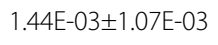 & $33.79 \pm 2.11$ & $0.97 \pm 0.06$ & $1.74 \mathrm{E}-06 \pm 1.16 \mathrm{E}-06$ & $0.99 \pm 5.39 \mathrm{E}-03$ \\
\hline $72 \mathrm{~h}$ & $3.61 \mathrm{E}-11 \pm 0.01 \mathrm{E}-12$ & $0.708 \pm 0.07$ & $6.69 \mathrm{E}-04 \pm 1.96 \mathrm{E}-05$ & $36.12 \pm 1.14$ & $0.98 \pm 0.07$ & $1.42 \mathrm{E}-06 \pm 9.74 \mathrm{E}-07$ & $0.98 \pm 8.25 \mathrm{E}-03$ \\
\hline
\end{tabular}


Fricke-Morse and Cole-Cole models. The total impedance $\mathrm{Z}(j \omega)$ can be defined as in Eq. 8:

$$
Z(j \omega)=Z_{\text {electrode-electrolyte interface }}+Z_{\text {Biological cell }}
$$

With respect to the Fricke-Morse model, the total impedance $\left[\mathrm{Z}_{\mathrm{FM}}(j \omega)\right]$ can be defined as in Eq. 9:

$$
Z_{F M}(j \omega)=\left[X_{C_{d l}} \| R_{d l}\right]+\left\{R_{e} \|\left[R_{i}+\left(X_{C_{m}} \| R_{m}\right)\right]\right\}
$$

Replacing the CPE of electrode-electrolyte interface $\left(\mathrm{CPE}_{\mathrm{et}}\right)$ and biological cell $\left(\mathrm{CPE}_{\text {cell }}\right)$ in Eq. 10 and 11:

$$
\begin{aligned}
C P E_{e t} & =\frac{1}{(j \omega)^{\alpha_{e t}} \cdot Q_{e t}} \\
C P E_{\text {cell }} & =\frac{1}{(j \omega)^{\alpha_{\text {cell }}} \cdot Q_{\text {cell }}}
\end{aligned}
$$

where $\omega$ is angular frequency $(\mathrm{rad} / \mathrm{s}),(\omega=2 \pi f) ; \alpha_{\mathrm{et}} \&$ $\alpha_{\text {cell }}$ are the CPE exponent of $\mathrm{CPE}_{\text {et }}$ and $\mathrm{CPE}_{\text {cell }}$ respectively, $Q_{\mathrm{et}}$ and $Q_{\text {cell }}$ are the $\mathrm{CPE}_{\mathrm{et}}$ and $\mathrm{CPE}_{\text {cell }}$ coefficient ( $\left.F / S^{\left(1-a_{\mathrm{et}}\right)}\right),\left(F / S^{\left(1-a_{\mathrm{cell}}\right)}\right)$ respectively.

Hence, the total impedance of the biological cell using Fricke-Morse model (Eq. 12):

$$
Z_{F M}(j \omega)=\frac{1}{(j \omega)^{\alpha_{e t}} \cdot Q_{e t}}+\left[\frac{R_{e} \cdot R_{i}}{R_{e}+R_{i}}+\frac{R_{e}-\frac{R_{e} \cdot R_{i}}{R_{e}+R_{i}}}{1+\left\{j \omega\left[\left(R_{e}+R_{i}\right) \cdot Q_{c e l l}\right]^{\left.1 / \alpha_{c e l l}\right\}^{\alpha_{c e l l}}}\right.}\right]
$$

It is found that the magnitude of the total impedance offered at low frequencies is dominated by lower branch i.e., $R_{e} \ll\left|R i+\mathrm{CPE}_{\text {cell }}\right|$; hence, the maximum level of current penetration in the biological cell occurs across the resistor $R_{e}$, i.e., the extracellular fluid/region. On the other hand, the magnitude of the total impedance offered at the higher frequencies is dominated by $R_{i} \gg \mid$ $\mathrm{CPE}_{\text {cell }}$, so the maximum level of current penetration in the medium occurs across $R_{e}$ and $R_{i}$, involving both intracellular and extracellular region to approximately yields the values $\left[\left(R_{e}, R_{i}\right) /\left(R_{e}+R_{i}\right)\right]$.

With respect to the Cole-Cole model, the total impedance $\left[\mathrm{Z}_{c c}(j \omega)\right]$ can be defined as in Eq. 13:

$$
Z_{C C}(j \omega)=\left[X_{C_{d l}} \| R_{C_{d l}}\right]+\left\{R_{\infty}+\left[X_{C} \| R_{0}\right]\right\}
$$

Replacing electrode-electrolyte interface and cell membrane with the corresponding CPE using Eqs. 10 and 11, then the total impedance becomes Eq. 14 (after solving)

$$
Z_{C C}(j \omega)=\frac{1}{(j \omega)^{\alpha_{e t}} \cdot Q_{e t}}+\left[R_{\infty}+\frac{R_{0}-R_{\infty}}{1+\left\{j \omega\left[\left(R_{0}-R_{\infty}\right) \cdot Q_{t}\right]^{\left.1 / \alpha_{\text {cell }}\right\}^{\alpha_{\text {cell }}}}\right.}\right]
$$

The magnitude of the total impedance offered at low frequencies is dominated by $R_{0}$, so the maximum level of current flow in the biological cell occurs around the extracellular region/fluid and only negligible current will pass through the biological cell due to very high impedance/resistance $R_{e}$ offer by cell-membrane. Whereas the magnitude of the total impedance offered at higher frequencies is dominated by $R_{\infty}$, so the maximum level of current in the biological medium/tissue flows inside the cell, i.e., through extracellular and intracellular region/ fluid $R_{e}$ and $R_{i}$, to approximately yields the values [ $R_{e}$. $\left.\left.R_{i}\right) /\left(R_{e}+R_{i}\right)\right]$.

Typically, $\alpha_{\text {et }}$ and $\alpha_{\text {cell }}$ are the dimensionless exponent parameter, which reflects the dielectric loss occurred due to an alteration in the non-homogeneous constant of electrode-electrolytic interface and the cellmembrane. Therefore, when $\alpha_{\text {et }}=1$, the $\mathrm{CPE}_{\text {et }}$ becomes ideal capacitor, i.e., $X_{\mathrm{Cdl}}$ and $\alpha_{\mathrm{et}}<1$ is the indicator which shows the level of inhomogeneity present in the electrode-electrolyte interface. On the other hand, when $\alpha_{\text {cell }}=1$, the $\mathrm{CPE}_{\mathrm{t}}$ becomes ideal capacitor, i.e., $X_{\text {cell }}$ and $\alpha_{\text {cell }}<1$ is the indicator which shows the level of inhomogeneity present in the dielectric medium.

Further, using these models it is possible to analyze the electrode-electrolyte-biological cell interfacing system. While the lower frequencies reflect interfacial effects of cell-substrate interactions, the higher frequencies reflect the morphological properties of the cell-layer formed on the electrode. Therefore, monitoring the bio-impedance spectra over a wide range of frequencies (depending upon the need) will provide us the information regarding the current state of cell functionality. The model parameters used in the present study is given in Table 1 . Our results comply with the previously reported papers that an increase in resistance $\left(R_{e}\right.$ and $\left.R_{0}\right)$ with empirical value $\left(\alpha_{\text {et }}\right.$ and $\left.\alpha_{\text {cell }}\right)$ and a decrease in $\mathrm{CPE}_{\text {cell }}$ and $\mathrm{CPE}_{\text {et }}$ are primarily due to the positive rate of cell proliferation (Bagnaninchi and Drummond 2011; Müller et al. 2011; Wegener et al. 2000; Xiao and Luong 2003) as observed from $6 \mathrm{~h}$ to $72 \mathrm{~h}$. Thus, change in concentration of the biological cell upon the metal electrode surface was modulated with the model parameters accordingly to divulge the dynamic behavior of any biological system.

\section{Conclusion}

This article evaluates the feasibility of a low-cost circuitry based portable, wireless ECIS system to assess the cellular dynamics of $\mathrm{C} 2 \mathrm{C} 12$ mouse myoblasts on artificial substrates. The proposed system is working notably well with cell culture assembly designed for studying the cellular functions such as cell adhesion, spreading, migration, and proliferation. The variation in physiological behavior can be well correlated with both changes in the 
electrical impedance and microscopic images data as well as using an equivalent electrical model. Hence, impedance technique is capable of specifying the peak magnitude and the phase change with respect to the functional parameters of cells such as cell attachment, spreading, migration and proliferation. From the tissue engineering point of view, impedance measurements of biological entities confer a high-throughput method with temporal resolution and real-time monitoring of tissue engineered constructs in their preliminary stages regarding cell attachment, proliferation and viability.

\section{Supplementary information}

Supplementary information accompanies this paper at https://doi.org/10. 1186/s40543-020-00223-9.

Additional file 1: Figure S1. Calibration graph using different $R_{1}$ values. Figure S2. shows the experimental data and its fitting. Figure S3. shows the flowchart for calculating the impedance; (a) Transmitting end, and (b) Receiving end. Figure S4. shows the rate of proliferation with respect to impedance (a) Time point vs. change in impedance and average cell count per image, and (b) Normalized impedance vs. frequency plot. Figure S5. shows morphology of the C2C12 cells present near the electrode (a) 6 h, (b) 18 h, (c) 36 h, (d) 48 h, and (e) 72 h; Scale bar: $20 \mu \mathrm{m}$. Table S1. Cost comparison of the device in USD.

\section{Abbreviations}

ECIS: Electric cell-substrate impedance sensing; EEC: Equivalent electrical circuit model; $\mathrm{CO}_{2}$ : Carbon dioxide incubator; RF: Radio frequency; VCCS: Voltage controlled constant current source; PBS: Phosphate-buffered saline; FBS: Fetal bovine serum; DMEM: Dulbecco's modified Eagle's medium high glucose; OP-AMP IC: Operational amplifier integrated circuit; Ag: Silver metal; CPE: Constant phase element; C: Cell membrane; $R_{1}$ : Resistance; $X_{C}$ : Reactance; DSO: Digital storage oscilloscope; DAQ: Data acquisition; $R_{\mathrm{i}}$ and $R_{\mathrm{e}}$ : Intracellular and extracellular resistance; $R_{0}$ and $R_{\infty}$ : Lower and higher frequency component resistance; $Z$ : Total impedance; $Z_{\text {re: }}$ True or real impedance; $Z_{\text {im: }}$ Imaginary impedance; $a$ : Dimensionless exponent parameter

\section{Acknowledgements}

All authors extend the acknowledgment for the logistical support provided by Indian Institute of Technology (Banaras Hindu University), Varanasi, during the completion of the study.

\section{Authors' contributions}

UK, SJ, NS, and SKM designed the experiment. UK and SP carried out the experimental studies. UK collected the data, did interpretation, and wrote the manuscript. CK, SKM, and NS helped to draft and revise the manuscript. All authors read and approved the final manuscript.

\section{Funding}

U.K. extend the acknowledgment for MHRD, India, for the Institute Doctoral Research fellowship and also for the BIRAC, An initiative under Department of Biotechnology, Ministry of Human Resource and Development (MHRD), Government of India for the grant and the SITARE-BIRAC-GYTI Award (Project ID 13246, 2019) under Students Innovations for Translation and Advancement of Research Explorations (SITARE) Scheme.

\section{Availability of data and materials}

Research data have been provided in the manuscript.

\section{Competing interests}

The authors declare that they have no competing interests.

\section{Author details}

${ }^{1}$ School of Biomedical Engineering, Indian Institute of Technology (Banaras Hindu University), Varanasi, Uttar Pradesh 221005, India. ${ }^{2}$ Department of
Electronics Engineering, Indian Institute of Technology (Banaras Hindu University), Varanasi, Uttar Pradesh 221005, India.

Received: 13 April 2020 Accepted: 11 June 2020

Published online: 30 June 2020

\section{References}

Abbaszadegan A, Ghahramani Y, Gholami A, Hemmateenejad B, Dorostkar S, Nabavizadeh $M$, et al. The effect of charge at the surface of silver nanoparticles on antimicrobial activity against gram-positive and gramnegative bacteria: A preliminary study. J Nanomater. 2015.

Akulov SA, Fedotov AA, Akulova AS. Errors in Determination of the Parameters of Bioelectric Impedance by the Transient-Function Method. Meas Tech. 2015.

Amini M, Hisdal J, Kalvøy H. Applications of bioimpedance measurement techniques in tissue engineering. J. Electr. Bioimpedance. Berlin: Sciendo; 2018;9(1).

Bagnaninchi PO, Drummond N. Real-time label-free monitoring of adiposederived stem cell differentiation with electric cell-substrate impedance sensing. Proc Natl Acad Sci U S A. 2011;108(16):6462-7.

Balavigneswaran CK, Mahto SK, Mahanta AK, Singh R, Vijayakumar MR, Ray B, et al. Cell proliferation influenced by matrix compliance of gelatin grafted poly(D,L-Lactide) three dimensional scaffolds. Colloids Surfaces B Biointerfaces [Internet]. Elsevier B.V.; 2018;166:170-8. Available from: https:// doi.org/10.1016/j.colsurfb.2018.03.014.

Bera TK. Bioelectrical Impedance and the Frequency Dependent Current Conduction Through Biological Tissues: A Short Review. IOP Conf. Ser. Mater. Sci. Eng. 2018.

Bosetti M, Massè A, Tobin E, Cannas M. Silver coated materials for external fixation devices: In vitro biocompatibility and genotoxicity. Biomaterials. 2002.

Cao H, Qiao Y, Liu X, Lu T, Cui T, Meng F, et al. Electron storage mediated dark antibacterial action of bound silver nanoparticles: Smaller is not always better. Acta Biomater. 2013.

Cho S. Electrical impedance analysis of cell growth using a parallel RC circuit model. BioChip J. [Internet]. 2011;5(4):327-32. Available from: https://doi.org/ 10.1007/s13206-011-5406-7.

Cho S. Electrical impedance simulation and characterization of cell growth using the fricke model. 2012:5228-32.

Coffman FD, Cohen S. Impedance measurements in the biomedical sciences. Biophotonics Pathol. Pathol. Crossroads. 2013.

Das D, Member GS, Kamil FA, Agrawal S, Biswas K, Das S. Fragmental frequency analysis method to estimate electrical cell parameters from bioimpedance study. 2014;63(8):1991-2000.

Elwakil BMAS. Extracting single dispersion Cole-Cole impedance model parameters using an integrator setup. 2012;107-10.

Gao A, Hang R, Huang X, Zhao L, Zhang X, Wang L, et al. The effects of titania nanotubes with embedded silver oxide nanoparticles on bacteria and osteoblasts. Biomaterials. 2014;.

Gelsinger ML, Tupper LL, Matteson DS. Cell line classification using electric cellsubstrate impedance sensing (ECIS). Int. J. Biostat. Berlin, Boston: De Gruyter; 2019;16(1).

Giaever I, Keese CR. Micromotion of mammalian cells measured electrically. Proc Natl Acad Sci U S A. 1991;88(17):7896-900.

Horwitz AF. Integrins and health. Sci Am. 1997.

Jing L. Culture, Differentiation and Transfection of C2C12 Myoblasts. BIOPROTOCOL. 2012

Kasiviswanathan U, Kumar C, Poddar S, Jit S, Mahto SK, Sharma N. Fabrication of MSM Based Biosensing Device for Assessing Dynamic Behavior of Adherent Mammalian Cells. IEEE Sens. J. [Internet]. 2020;1-1. Available from: https:// ieeexplore.ieee.org/document/9080083/.

Keese CR. Monitoring fibroblast behavior in tissue culture with an applied electric field. 1984;81(June):3761-4.

Kenchetty P, Miura T, Uno S. Computer simulation for electrochemical impedance of a living cell adhered on the interdigitated electrode sensors. Japanese J. Appl. Phys. Regul. Pap. [Internet]. 2019 [cited 2019 Sep 26]; Available from: https://doi.org/10.7567/1347-4065/ab00f0.

Khalili AA, Ahmad MR. A Review of cell adhesion studies for biomedical and biological applications. Int J Mol Sci. 2015.

Kumar Y, Kumar H, Rawat G, Kumar C, Sharma A, Pal BN, et al. Colloidal ZnO quantum dots based spectrum selective ultraviolet photodetectors. IEEE Photon Technol Lett. 2017;29(4):361-4. 
Kyle UG, Bosaeus I, De Lorenzo AD, Deurenberg P, Elia M, Gómez JM, et al. Bioelectrical impedance analysis - Part I: Review of principles and methods. Clin Nutr. 2004

Liu Q, Yu J, Xiao L, Tang JCO, Zhang Y, Wang P, et al. Impedance studies of biobehavior and chemosensitivity of cancer cells by micro-electrode arrays. Biosens Bioelectron. 2009;24(5):1305-10.

Lo CM, Keese CR, Giaever I. Impedance analysis of MDCK cells measured by electric cell-substrate impedance sensing. Biophys. J. [Internet]. Elsevier; 1995; 69(6):2800-7. Available from: https://doi.org/10.1016/S0006-3495(95)80153-0.

Lu YY, Huang JJ, Huang YJ, Cheng KS. Cell growth characterization using multielectrode bioimpedance spectroscopy. Meas. Sci. Technol. 2013;

Maundy B, Elwakil AS. Extracting single dispersion Cole-Cole impedance model parameters using an integrator setup. Analog Integr. Circuits Signal Process. 2012;

Mondal D, RoyChaudhuri C. Real time in vitro monitoring and impedance modeling of mammalian cell activities on planar ECIS and micro/nano patterned cytosensors. ISSS J. Micro Smart Syst. 2018;

Müller J, Thirion C, Pfaffl MW. Electric cell-substrate impedance sensing (ECIS) based real-time measurement of titer dependent cytotoxicity induced by adenoviral vectors in an IPI-2I cell culture model. Biosens Bioelectron. 2011; 26(5):2000-5.

Pan Y, Hu N, Wei X, Gong L, Zhang B, Wan H, et al. 3D cell-based biosensor for cell viability and drug assessment by $3 \mathrm{D}$ electric cell/matrigel-substrate impedance sensing. Biosens. Bioelectron. [Internet]. Elsevier B.V.; 2019; 130(August 2018):344-51. Available from: https://doi.org/10.1016/j.bios.2018 09.046 .

Park $\mathrm{H}$, Hong $\mathrm{Y}$, Jun HS, Cho ES, Cho S. DAQ based Impedance Measurement System for Low Cost and Portable Electrical Cell-Substrate Impedance Sensing. Biochip J. 2018;12(1):18-24.

Parviz M, Gaus K, Gooding JJ. Simultaneous impedance spectroscopy and fluorescence microscopy for the real-time monitoring of the response of cells to drugs. Chem Sci. 2017:8(3):1831-40.

Pasqualotto E, Ferrario A, Scaramuzza M, De Toni A, Maschietto M. Monitoring electropermeabilization of adherent mammalian cells through electrochemical impedance spectroscopy. Procedia Chem [Internet]. 2012;6: 79-88 Available from: https://doi.org/10.1016/j.proche.2012.10.133.

Pérez P, Huertas G, Maldonado-Jacobi A, Martín M, Serrano JA, Olmo A, et al. Sensing cell-culture assays with low-cost circuitry. Sci Rep. 2018;8(1):1-11.

Pethig R, Kell DB. The passive electrical properties of biological systems: their significance in physiology, biophysics and biotechnology. Phys Med Biol. 1987.

Plunger B, Choi CK, Sparer TE. Electrical cell-substrate impedance sensing for measuring cellular transformation, migration, invasion, and anticancer compound screening. Cancer Metastasis - Biol. Treat. 2012;

Prendecka S, Frankowski J, Sobieszek G, Kapka-Skrzypczak L, SkwarekDziekanowska A, Maleckaa-Masalska T. Electric Cell Substrate Impedance Sensing (ECIS) as a unique technique in cancer metastasis research. J. PreClinical Clin. Res. -; 2018;12(4).

Rahman ARA, Register J, Vuppala G, Bhansali S. Cell culture monitoring by impedance mapping using a multielectrode scanning impedance spectroscopy system (CellMap). Physiol Meas. 2008.

Sales A, Ende K, Diemer J, Kyvik AR, Veciana J, Ratera I, et al. Cell Type-Dependent Integrin Distribution in Adhesion and Migration Responses on ProteinCoated Microgrooved Substrates. ACS Omega. 2019;4(1):1791-800.

Siddiquei HR, Nordin AN, Ibrahimy MI, Arifin MA, Sulong NH, Mel M, et al. Electrical cell-substrate impedance sensing (ECIS) based biosensor for characterization of DF-1 cells. Int. Conf. Comput. Commun. Eng. ICCCE'10. 2010;6(0940111):11-3

Szulcek R, Bogaard HJ, van Nieuw Amerongen GP. Electric cell-substrate impedance sensing for the quantification of endothelial proliferation, barrier function, and motility. J Vis Exp. 2014;85:1-12

Trainito $\mathrm{Cl}$, Français O, Le Pioufle B. Analysis of pulsed electric field effects on cellular tissue with Cole-Cole model: Monitoring permeabilization under inhomogeneous electrical field with bioimpedance parameter variations. Innov. Food Sci. Emerg. Technol. 2015;

Tsong TY. Electroporation of Cell Membranes. In: Neumann E, Sowers AE, Jordan CA, editors. Electroporation electrofusion cell biol. [Internet]. Boston, MA: Springer US; 1989. p. 149-63. Available from: https://doi.org/10.1007/978-14899-2528-2_9.
Uvanesh K, Jain S, Das S, Champaty B, Singh VK, Das KC, et al. Development of a continuous impedance monitoring system: A study to monitor D-glucose concentration. Int. J. Electrochem. Sci. 2015;10(1).

Vajanthri KY, Sidu RK, Poddar S, Singh AK, Mahto SK. Combined substrate micropatterning and FFT analysis reveals myotube size control and alignment by contact guidance. Cytoskeleton. 2019;

Wegener J, Keese CR, Giaever I. Electric cell-substrate impedance sensing (ECIS) as a noninvasive means to monitor the kinetics of cell spreading to artificial surfaces. Exp Cell Res. 2000;259(1):158-66.

Xiao C, Luong JHT. On-line monitoring of cell growth and cytotoxicity using electric cell-substrate impedance sensing (ECIS). Biotechnol Prog. 2003;19(3): 1000-5.

Xiaoa C, Luong JHT. A simple mathematical model for electric cell-substrate impedance sensing with extended applications. Biosens. Bioelectron. [Internet]. Elsevier B.V.; 2010;25(7):1774-80. Available from: https://doi.org/10. 1016/j.bios.2009.12.025.

Zimmermann V, Vienken J. Electric Field-Induced Cell-To-Cell Fusion. J Membr Biol. 1982;67:165-82.

\section{Publisher's Note}

Springer Nature remains neutral with regard to jurisdictional claims in published maps and institutional affiliations.

\section{Submit your manuscript to a SpringerOpen ${ }^{\circ}$ journal and benefit from:}

- Convenient online submission

- Rigorous peer review

- Open access: articles freely available online

High visibility within the field

- Retaining the copyright to your article

Submit your next manuscript at $\boldsymbol{\nabla}$ springeropen.com 